\title{
Analysis and Repair of the Fault of Electric Power Special Optical Cable
}

\author{
Lishuai $\mathrm{He}^{1}$, Zhitong $\mathrm{Liu}^{2}$, Bin $\mathrm{Lu}^{1}$, Shuo Shang ${ }^{3}$, Xingcai Shi ${ }^{4}$, Wei Ma ${ }^{5}$, Yuhui \\ Zhang $^{5}$, Yadong $\mathrm{Si}^{6}$, Chuanbo $\mathrm{Liu}^{7}$ \\ ${ }^{1}$ Maintenance Branch Company, Liaoning Electric Power Company Limited, State Grid, China \\ ${ }^{2}$ Shenyang Power Supply Company, Liaoning Electric Power Company Limited, State Grid, China \\ ${ }^{3}$ Huludao Power Supply Company, Liaoning Electric Power Company Limited, State Grid, China \\ ${ }^{4}$ Technical Training Center, Liaoning Electric Power Company Limited, State Grid, China \\ ${ }^{5}$ LiaoyangPower Supply Company, Liaoning Electric Power Company Limited, State Grid, China \\ ${ }^{6}$ Chaoyang Power Supply Company, Liaoning Electric Power Company Limited, State Grid, China \\ ${ }^{7}$ Fushun Power Supply Company, Liaoning Electric Power Company Limited, State Grid, China
}

Keywords: electric power special optical cable; ADSS; OPGW; operation and maintenance; fault treatment

\begin{abstract}
Electric power special optical cable is an important part of electric power information communication system. Electric power special optical fiber cable, can be simply understood as the optical cable and power line belongs to the same tower erection, the optical cable does not need to be set up separately. Including ADSS (ADSS), OPGW (OPGW), winding cable (GWWOP), the phase of optical fiber composite (OPPC) etc.. Electric power special optical cable is in the state of operation, when the fault occurs, it is needed to be repaired immediately. In this paper, the common faults of electric power special optical cable and its analysis methods are discussed, which provide the theoretical support for the operation and maintenance of the optical cable.
\end{abstract}

\section{Introduction}

In the Fushun area, electric power special optical fiber cable has covered all stations, including 1 500kV substation, $13220 \mathrm{kV}$ substations, $9666 \mathrm{kV}$ substations, and all of the basic office. Specific business, including video surveillance, power environment monitoring, IP telephone service, power dispatching business [3], MIS network business, relay protection automation operation and maintenance business and production office demand and other services. At present, in Fushun, there are a total of $8888 \mathrm{~km}$ special optical fiber cable. Due to the wide coverage area, long distance, long-term exposure to atmospheric environment, the failure is inevitable.

\section{Overview of Electric Power Special Optical Cable}

The construction of electric power special optical fiber cable, can be synchronized with the power grid construction, make full use of the tower of power system and the high voltage line resources, but also saves a lot of construction costs [4]. Suitable for being installed in the tower with different voltage levels, can also be laid in a pipeline. The main types of electric power special optical cable, ADSS (ADSS), OPGW (OPGW), winding cable (GWWOP), the phase of optical fiber composite (OPPC) etc.. In Fushun electric power communication network, the main use is two kinds of optical fiber cable, ADSS, OPGW.

\section{ADSS.}

ADSS optical cable, Chinese name is all dielectric self - supporting optical cable [1].

ADSS cable has the advantages of light weight, no metal, small cable diameter, non metal structure, good insulation, anti lightning, anti corrosion, good performance, widely used in electric power communication network system.

\section{OPGW.}

OPGW optical cable, Chinese name is the optical fiber composite overhead ground wire. 
With the line lightning protection and communication of the dual function, with good mechanical and electrical properties of [2]. Anti distortion and anti compression, anti tensile properties, suitable for the new $66 \mathrm{kV}$ and above lines. The disadvantage is that the construction and fault repair, the line must be the state of power outage.

\section{Common Fault Analysis of Electric Power Special Optical Cable}

\section{External Damage Factors.}

May 12, 2014 morning. On duty officer found that there is a serious communication transmission network management alarm. The warning message is that the transmission communication network is interrupted. The alarm information involves two substations, $66 \mathrm{kV}$ Xin Bin substation, $66 \mathrm{kV}$ North Siping substation. The communications professional transport inspection officers immediately rushed to the Xinbin substation, carried out on the 66kVOPGW overhead optical cable survey. In the substation station, OTDR (optical time domain reflector, a device that can obtain the useful information of the optical fiber cable line [5]) can be used to test the fiber optic cable channel failure, the waveform is shown in figure 1. According to the graph analysis, the location is about 190 meters, the optical path is interrupted. Maintenance personnel along the fiber cable path to carry out the line inspection. Found serious tilt phenomenon in fourth power tower. A careful view found that the outer sheath of the optical fiber cable is damaged.

Based on traces, maintenance personnel to determine the cable break cause of the malfunction is caused by lifting machinery. Damaged optical fiber cable segment is re replaced, optical path recovery, the affected communications business to resume normal operation.

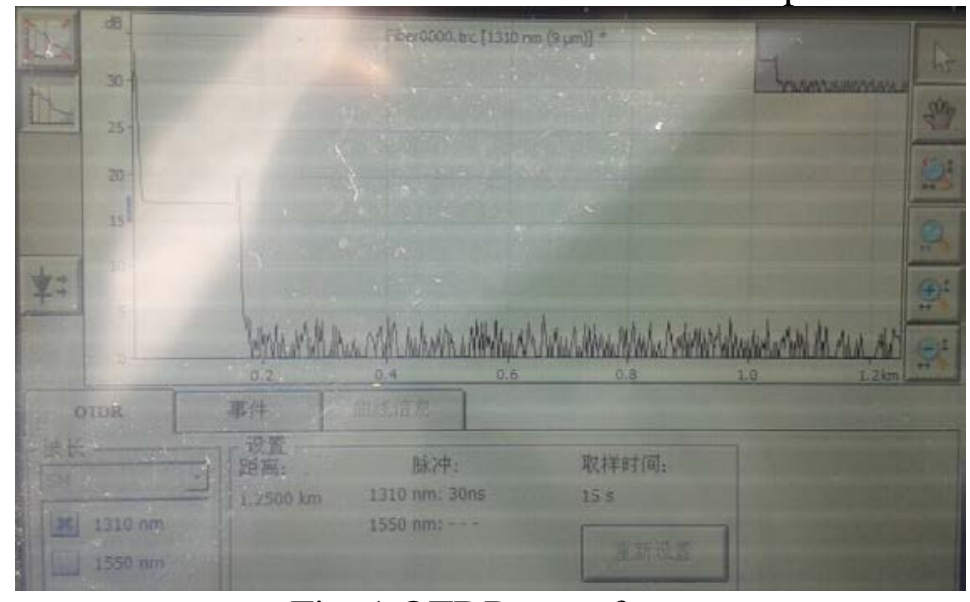

Fig. 1 OTDR waveform

\section{Improper Construction Factors.}

In March 12, 2013, in the 66kV Kuang Zi substation, communication engineering construction site. After the fiber optic cable is laid, the communication professionals will be ready to debug the fiber channel. Commissioning work is related to the two substation terminal, 66kV Kuang $\mathrm{Zi}$ substation, 220kV Qian Wu substation. 2 groups of people were using handheld optical power meter and hand-held light source equipment, to complete the debugging work of the fiber channel. After passing through the channel one by one after the test did not succeed. At the same time, the construction staff also confirmed that the optical fiber cable connection and the terminal ODF (fiber optic distribution unit) welding are no quality problems. Then use the OTDR device to test the fiber cable, the results show that there is an interruption at a distance of 125.5 meters. Field personnel according to the actual conditions of the survey analysis, optical cable connector box in the terminal tower, distance communication room is about 60 meters, optical interrupt does not occur in the optical fiber cable connector box. Preliminary determination, location in the two towers, but did not find significant problems (visual judgment). OPGW cable was put down by the construction staff. After careful examination found that in the OPGW cable 125.5 meters or so, aluminum alloy wire (AA) has a slight extrusion damage. The schematic diagram of the fault optical cable is shown in Figure 2. 
Optical fiber cable fault reason is as follows, in the course of the cable laying, the construction personnel cable traction is not correct, resulting in OPGW cable bending extrusion damage caused by internal optical fiber broken. Damaged fiber cable is replaced, the business channel debugging work completed successfully.

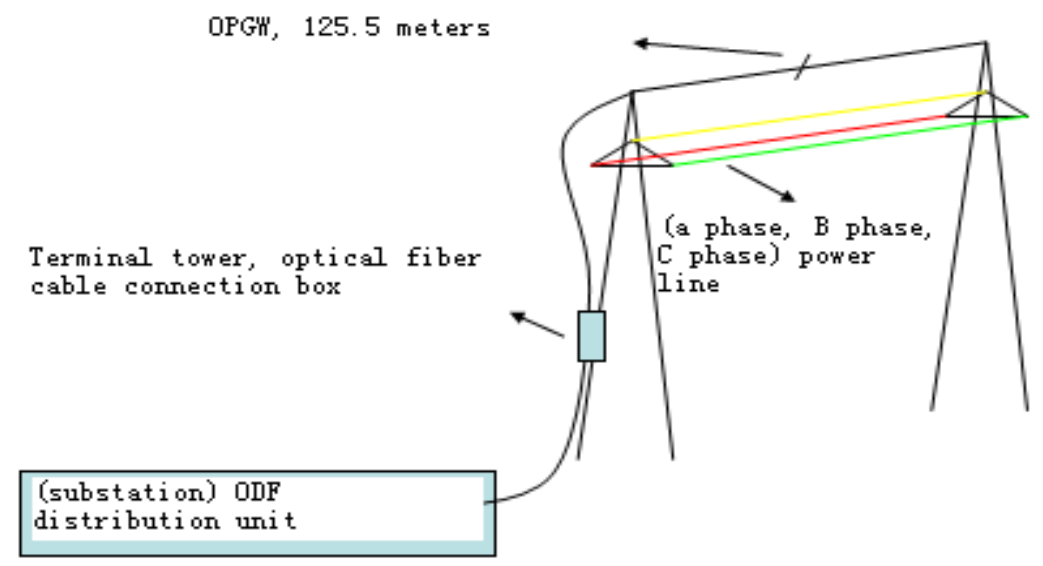

Fig. 2 Schematic diagram of failure optical fiber cable

\section{External Environmental Factors.}

In July 16, 2013, the "big Siping town", the fault of power supply business hall network. Operation and maintenance personnel immediately rushed to the business site survey. The business hall and the substation are connected through the ADSS-12 core overhead optical fiber cable. After the examination and repair personnel examine the data network switch equipment, the indicator lamp status of the port is found to be abnormal, and the preliminary judgment is the light path problem. Maintenance personnel to carry out the optical fiber cable alternate channel test. The test data are shown in table 1 . It is concluded that the spare fiber core (distance value, attenuation value) are in the normal range, there is no external damage to the optical fiber cable. Combined with the use of optical fiber core, decided to use the 2 core spare fiber channel. After replacing the optical fiber channel, the device indicates that the lamp is back to normal, and the network service is returned to normal. The measured attenuation values of the fiber channel are $-8.243 \mathrm{~dB},-5.463 \mathrm{~dB}$. The full loss value of the fault fiber channel exceeds the threshold value of the transmission equipment.

Optical fiber cable business interruption because, in the long-term use of the process, the influence of fiber channel stress and temperature change, led to the core attenuation value changes, long time accumulation, resulting in the decline of the core channel quality, thus making the business interruption.

Table 1 ADSS-12 core overhead optical cable test record

\begin{tabular}{|l|l|l|l|l|l|l|l|l|l|l|l|l|}
\hline $\begin{array}{l}\text { Serial } \\
\text { number }\end{array}$ & 1 & 2 & 3 & 4 & 5 & 6 & 7 & 8 & 9 & 10 & 11 & 12 \\
\hline State & $\begin{array}{l}\text { In } \\
\text { use }\end{array}$ & In use & free & free & free & free & free & free & free & free & free & free \\
\hline $\begin{array}{l}\text { Distance } \\
(\mathrm{km})\end{array}$ & & $\begin{array}{l}16.1 \\
91\end{array}$ & $\begin{array}{l}16.1 \\
95\end{array}$ & $\begin{array}{l}16.1 \\
96\end{array}$ & $\begin{array}{l}16.1 \\
92\end{array}$ & $\begin{array}{l}16.1 \\
92\end{array}$ & $\begin{array}{l}16.1 \\
87\end{array}$ & $\begin{array}{l}16.1 \\
94\end{array}$ & $\begin{array}{l}16.1 \\
92\end{array}$ & 16.196 & 16.196 \\
\hline $\begin{array}{l}\text { Loss } \\
(\mathrm{dB})\end{array}$ & $\begin{array}{l}4.66 \\
5\end{array}$ & $\begin{array}{l}4.59 \\
1\end{array}$ & 4.55 & $\begin{array}{l}4.63 \\
2\end{array}$ & $\begin{array}{l}4.63 \\
2\end{array}$ & $\begin{array}{l}4.67 \\
0\end{array}$ & $\begin{array}{l}4.63 \\
0\end{array}$ & $\begin{array}{l}4.63 \\
2\end{array}$ & 4.55 & 4.55 \\
\hline Remarks & $\begin{array}{l}8.243 \\
\mathrm{~dB}\end{array}$ & $\begin{array}{l}5.463 \\
\mathrm{~dB}\end{array}$ & & & & & & & & & $\begin{array}{l}\text { Alternate } \\
\text { channel }\end{array}$ & $\begin{array}{l}\text { Alternate } \\
\text { channel }\end{array}$ \\
\hline
\end{tabular}

\section{Material Quality Factor.}

In February 18, 2014, the communication scheduling in the inspection found that the ring network generated alarm. The warning message is that the transmission communication network is 
interrupted. The alarm information involves two substations, $66 \mathrm{kV}$ Da Suhe substation, 66kV Wan Dianzi substation. After verification, no line outage maintenance operations, dispatching immediately arrange staff to the site survey. After arriving at the scene confirmed that the substation is not a power outage, the DC power supply is also normal. It is found that the transmission equipment alarm indicator light is on, the preliminary judgment, the reason is the power communication optical fiber cable. In the $66 \mathrm{kV}$ Da Suhe substation, using OTDR equipment on the optical cable test found that in a distance of 1.6 kilometers from the substation there is a point of interruption. Through comparison with technical data, it is found that this is probably the location of the optical cable connection box. Inspection and maintenance personnel found that power communication optical fiber cable box is covered with snow and ice. After the box is opened, the interior is frozen. Emergency repair personnel decided to re fuse 24 core OPGW, and replace the power communication optical fiber cable connection box. After the end of the operation, the field staff received a notice of the communication dispatcher, the alarm has been eliminated, the communication service recovery.

The failure of the optical fiber cable for the following reasons. A small amount of optical fiber cable box factory, inspection is not strict, there is a quality risk. Fiber cable connection box in long term use,coupled with poor weather in Fushun in winter, freezing damage to the fiber cable lines, leading to the interruption of power communication optical fiber cable.

\section{Optical Cable Fault Repair}

\section{Principles of Fault Repair.}

(1)The first task is to restore business, followed by the system repair.

(2)The primary task is to deal with the fault of the main backbone communication network. Second step task, the fault treatment of regional communication network.

(3)Firstly, find the reason of failure in this substation. The second is to find fault causes in the other end of the transformer substation.

(4)According to the principle of different levels of treatment. When there are two or more faults, the priority should be given to deal with the large scale or higher level fault.

\section{Fault Repair Process.}

(1)To determine the location of the fault.

(2)Ready to repair materials, information, etc..

(3)The emergency repair teams to coordinate and communicate in real time.

(4)The unified arrangement of the communication scheduling.

(5)Repair of the optical fiber cable line, replace the cable or connector box.

(6)Business recovery.

(7)Cleaning the scene.

(8)The line information is updated in a timely manner.

\section{Fault Repair Measures.}

(1) Method 1, the attenuation value control method. When the transmission performance of the fiber channel is not stable, such as the attenuation value of the core channel is not within the specified range. By adding a light attenuation element or an optical power amplifier element, the fiber core channel is suitable for the stable transmission of optical signals.

(2) Method 2, alternate channel method. When the spare core cable channel exists, the affected business can be switched to standby core channel. After the completion of the operation in a timely manner to the communication scheduling report, to confirm whether the failure process is completed.

(3) Method 3, roundabout route method. In the failure of the fiber optic cable without spare fiber core, through the way to find the running data, the most suitable detour path is found. The affected service can be transferred via other one or more nodes. After the completion of the operation in a timely manner to the communication scheduling report, to confirm whether the failure process is completed. 
(4) Method 4, grade channel method. Failure of the fiber optic cable channel has the following status, for example, has been damaged many times, the number of spare fiber core is not enough, and there is no other detour path can be used. In accordance with the different levels of the circuit, if necessary, take up a secondary business fiber channel, the recovery of important business optical path. After the event, in time to develop a fault recovery scheme for optical fiber cable, the failure of a comprehensive repair cable. After the end of the timely reporting to the communication scheduling, to confirm whether the fault is processed.

(5) Method 5, direct processing method. In the case of the above fault treatment measures can not be implemented, it should be carried out in a timely manner to the site construction. In the fault fiber cable position processing, after the completion of a timely manner to the communication scheduling report, to confirm whether the failure process is completed.

\section{Conclusions}

In short, the fault analysis and research of electric power special optical cable is very important for the safety and reliability of power information communication platform and power system. Different repair measures should be adopted for different types of optical cable failure. Electric power communication personnel need to continue working diligently in the daily work, work hard to study, sum up the work experience and lessons learned, to extract more abundant optical fiber cable fault causes and repair measures. To improve the operation and management of electric power special optical cable, this paper only makes reference to the technical personnel of the same industry.

\section{References}

[1] Hanxin Yang.Application of ADSS optical cable in electric power communication network."Jiangsu electrical engineering".2007 03

[2] Junhua Huang, Minghai Fan, Haifeng Jin, Feiyan Zhang. Main technical characteristics of OPGW optical cable. Proceedings of the Tenth National Conference on optical fiber communication and the eleventh session of the integrated optics (OFCIO '2001). 2001

[3] Daoyong Guo. Research on the construction and maintenance of ADSS and OPGW of electric power special optical cable. "Heilongjiang science and technology information". 201413

[4] Rong Zuo.Application analysis of ADSS electric power special optical cable in power line erection."Value engineering". 201027

[5] Xiaolin Cheng. Using OTDR to carry on the accurate test, "the Sichuan communication technology". 200101 